\title{
The stomach talks with the pituitary
}

Kojima M, Hosoda H, Date Y, Nakazato M, Matsuo $\mathrm{H}$, Kangawa $\mathrm{K}$. Ghrelin is a growth-hormonereleasing acylated peptide from the stomach. Nature 1999;402:656-60.

\section{Abstract}

Small synthetic molecules called growth-hormone secretagogues (GHSs) stimulate the release of growth hormone $(\mathrm{GH})$ from the pituitary. They act through GHS-R, a G-protein-coupled receptor for which the ligand is unknown. Recent cloning of GHS-R strongly suggests that an endogenous ligand for the receptor does exist and that there is a mechanism for regulating GH release that is distinct from its regulation by hypothalamic growthhormone-releasing hormone (GHRH). We now report the purification and identification in rat stomach of an endogenous ligand specific for GHS-R. The purified ligand is a peptide of 28 amino acids, in which the serine 3 residue is $n$-octanoylated. The acylated peptide specifically releases $\mathrm{GH}$ both in vivo and in vitro and $O$ - $n$-octanoylation at serine 3 is essential for the activity. We designate the $\mathrm{GH}$ releasing peptide 'ghrelin' (ghre is the Proto-IndoEuropean root of the word 'grow'). Human ghrelin is homologous to rat ghrelin apart from two amino acids. The occurrence of ghrelin in both rat and humans indicates that $\mathrm{GH}$ release from the pituitary may be regulated not only by hypothalamic GHRH but also by ghrelin.

\section{Comment}

The textbook view of the hormonal control of the release of growth hormone $(\mathrm{GH})$ from the anterior pituitary gland is that it is exerted in two principally different ways. There are two releasing factors emanating from nerve nuclei in the hypothalamus: growth hormone releasing hormone and somatostatin, the latter hormone inhibiting the release of GH. Furthermore, circulating insulin-like growth factor (IGF) I, the release of which is controlled by $\mathrm{GH}$, functions together with $\mathrm{GH}$ itself as negative feedback factors with regard to secretion of $\mathrm{GH}$. Hence with increasing plasma levels of IGF-I and/or GH, the release of $\mathrm{GH}$ is inhibited. $^{1}$

In 1984 a synthetic hexapeptide, containing two D-amino acid residues, was demonstrated to cause the release of GH. ${ }^{2}$ Subsequently, it was shown that this peptide and other non-peptidergic GH secretagogues (GHSs) did not act via any of the known cell membrane receptors controlling GH secretion. The effect of GHS on GH release was "physiological" - that is, the increased GH secretion exhibited in the normal pulsatile pattern. Using molecular biology techniques it was possible to clone the receptor for these growth hormone secretagogues. ${ }^{3}$ Moreover, the intracellular events following stimulation of the receptor (including increased calcium concentrations) were elucidated. The nature of the physiological ligand and its site of production was, however, not known. Hence this research field was in the somewhat peculiar situation of having a well characterised cell membrane receptor as well as knowing in some detail the intracellular events occurring on stimulation of the receptor without knowledge of how and when it was physiologically stimulated.

The physiological agonist to the GHS receptor now seems to have been characterised. In a recent report in Nature, Kojima et al reported that they isolated and chemically defined a peptide from the rat stomach that functions as a ligand to the earlier defined receptor for GHSs. The putative new hormone, named ghrelin, is made up of 28 amino acid residues with a molecular mass of $3315 \mathrm{Da}$ and exists in large amounts in the stomach. The prepro-hormone is a 117 amino acid residue protein with $80 \%$ identity between humans and rats. Only two of 28 amino acids in ghrelin differ between the two species indicating a high degree of evolutionary conservation. From a chemical point of view the isolated peptide hormone is unique in that the serine 3 residue is $n$-octanoylated. This seems to be of great importance for the function of ghrelin, as a peptide devoid of acylated serine did not cause an increase in intracellular calcium concentration in cells in vitro.

The proposed hormone is localised to cells in the oxyntic glands. The appearance of ghrelin cells suggests an endocrine function of the cells. Furthermore, it was found in neurones localised to the hypothalamic arcuate nucleus, a part of the hypothalamus involved in the control of GH secretion. The putative new hormone evokes secretion only of $\mathrm{GH}$ and not of any other hormone produced in the anterior lobe of the pituitary when tested both in vitro and in vivo. Plasma concentrations in humans are quite high (approximately $100 \mathrm{fmol} / \mathrm{ml}$ ). The ghrelin receptor is, as expected, found in the hypothalamus and the pituitary. Interestingly, mRNA analyses indicate that ghrelin receptors are also expressed in the heart, lungs, pancreas, intestine, and adipose tissue. Taken together the reported results clearly suggest a hormone function of the newly isolated gastric peptide.

The concept of a gastrointestinal hormone influencing release of GH from the pituitary is new. The stimulus needed to release ghrelin is not known. It seems reasonable to assume that ghrelin is secreted in connection with food intake in some way via chemical and/or mechanical stimuli. If so, the cells of the organism are under an increased influence of $\mathrm{GH}$ when food is being absorbed from the intestine. This seems appropriate from a teleological point of view considering the protein anabolic effects of GH. Demonstration of expression of 
ghrelin receptors in tissues other than the hypothalamus and pituitary suggests other as yet unknown functions of ghrelin.

Department of Physiology,

O LUNDGREN

Göteborg University,

Box 432, S-405 30 Göteborg, Sweden

Email: ove.lundgren@fysiologi.gu.se
1 Robinson ICA. Control of growth hormone (GH) release by GH secretagogues. In: Chadwick DJ, Goode JA, eds. Mechanisms and biological significance of pulsatile hormone secretion (Novartis Foundation Symposium 227). John Wiley and Sons Ltd, 2000;206-20.

2 Bowers CY, Momany F, Reynolds GA, Hong A. On the in vitro and in vivo acitvity of a new synthetic hexapeptide that acts on the pituitary to specifically release growth hormone. Endocrinology 1984;114:1537.

3 Howard AD, Feighner SD, Cully DF, et al. A receptor in pituitary and hypothalamus that functions in growth hormone release. Science 1996;273: h74-7. 